University of Nebraska - Lincoln

DigitalCommons@University of Nebraska - Lincoln

Sociology Department, Faculty Publications

Sociology, Department of

2009

Risk Factors for Trading Sex among Homeless Young Adults

Kimberly A. Tyler

University of Nebraska-Lincoln, kim@ktresearch.net

Follow this and additional works at: https://digitalcommons.unl.edu/sociologyfacpub

Part of the Sociology Commons

Tyler, Kimberly A., "Risk Factors for Trading Sex among Homeless Young Adults" (2009). Sociology Department, Faculty Publications. 39.

https://digitalcommons.unl.edu/sociologyfacpub/39

This Article is brought to you for free and open access by the Sociology, Department of at DigitalCommons@University of Nebraska - Lincoln. It has been accepted for inclusion in Sociology Department, Faculty Publications by an authorized administrator of DigitalCommons@University of Nebraska - Lincoln. 


\section{Risk Factors for Trading Sex among Homeless Young Adults}

\author{
Kimberly A. Tyler \\ Department of Sociology \\ University of Nebraska-Lincoln \\ Lincoln, NE 68588-0324, USA \\ email kim@ktresearch.net
}

\begin{abstract}
Although numerous homeless youth report trading sex, few studies have examined risk factors associated with trading sex and even fewer have employed multivariate analyses to examine this relationship, even though trading sex is associated with many negative health outcomes. Based on a sample of 151 homeless young adults in the midwestern United States, logistic regression analyses revealed that for each additional year of age, youth were $37 \%$ more likely to have traded sex $(\mathrm{AOR}=1.37 ; 95 \% \mathrm{CI}=.99-1.90)$. White youth were $84 \%$ less likely to have traded sex than nonwhite youth $(\mathrm{AOR}=.16$; 95\% CI $=.03-.77)$. Furthermore, youth who had been employed full time were $80 \%$ less likely to have traded sex $(\mathrm{AOR}=.20 ; 95 \% \mathrm{CI}=.05-.85)$. For every one unit increase in depressive symptoms, there was an $11 \%$ increase in the likelihood of ever having traded sex $(\mathrm{AOR}=1.11 ; 95 \% \mathrm{CI}=.99-1.24)$. Additionally, those who had friends who traded sex were approximately five times more likely to have ever traded sex themselves compared to those with no friends who had traded sex $(\mathrm{AOR}=5.17$; $95 \% \mathrm{CI}=.95-28.12$ ). Finally, youth who were propositioned to trade sex were almost five and one-half times more likely to have ever done so compared to youth who had not been propositioned $(\mathrm{AOR}=5.45 ; 95 \% \mathrm{CI}=1.02-29.17)$. Overall, the results have important implications for the health and well-being of this high-risk population.
\end{abstract}

Keywords: trading sex, friends trading sex, depression, homelessness

Published in Archives of Sexual Behavior (2009); doi 10.1007/ s10508-007-9201-4 ASB is the Official Publication of the International Academy of Sex Research. Copyright (C) 2007 Springer Science+Business Media, LLC. Used by permission. http://www.springer.com/public+health/journal/10508

Submitted August 10, 2006; revised January 24, 2007; accepted March 7, 2007; published online July 26, 2007.

\section{Introduction}

Research has demonstrated that numerous homeless youth engage in deviant subsistence strategies, such as trading sex as a means of survival. Trading sex, which is typically defined as exchanging sex for specific items such as food, shelter, money, or drugs can be differentiated from prostitution, which is typically done exclusively for economic gain (Overall, 1992). Because of their lack of resources, trading sex may be viewed as a practical solution to the current financial situation of homeless youth (Hagan \& McCarthy, 1997; Mallory \& Stern, 2000; Van Leeuwen et al., 2004; Whitbeck \& Hoyt, 1999). Rates of trading sex among homeless youth have been found to vary significantly by study from approximately $11 \%$ to $46 \%$ (Beech, Myers, \& Beech, 2002; Greenblatt \& Robertson, 1993; Greene, Ennett, \& Ringwalt, 1999; Halcon \& Lifson, 2004; Kipke, Unger, O'Connor, Palmer, \& LaFrance, 1997; Kral, Molnar, Booth, \& Watters, 1997; Martinez et al., 1998; Tyler \& Johnson, 2006; Van Leeuwen et al., 2004).

Trading sex among homeless youth is often thought to be a last resort and is a survival strategy that is generally employed less frequently compared to other delinquent subsistence strategies, such as conning and stealing (Hagan \& McCarthy, 1997; Whitbeck \& Hoyt, 1999). Although some research has examined trading sex as a predictor of sexual victimization (Tyler, Hoyt, \& Whitbeck, 2000; Tyler, Hoyt, Whitbeck, \& Cauce, 2001), very few studies have examined other risk factors associated with trading sex among homeless youth. Fewer studies have employed multivariate analyses to examine this relationship even though trading sex is associated with numerous negative health outcomes, such as being sexually victimized, attempting suicide, contracting sexually transmitted diseases, and becoming pregnant (Greene et al., 1999; Tyler et al., 2000; Tyler, Whit- 
beck, Hoyt, \& Yoder, 2000). Given these negative health outcomes, it is important to understand the correlates of trading sex among homeless young adults so that caseworkers and service providers may effectively intervene before trading sex becomes a way of life.

\section{Family background}

Family background characteristics of homeless youth (e.g., number of times they have run from their home and sexual abuse) are possible precursors to engaging in potentially high-risk behaviors such as trading sex. Running away from home numerous times and spending more time away from home have been found to be positively associated with trading sex (Greene et al., 1999; Tyler et al., 2001) and other deviant subsistence strategies (Whitbeck \& Hoyt, 1999). Youth who run away numerous times spend more time away from home and may be at greater risk for trading sex due to both exposure and lack of resources. Research also finds that homeless youth who have experienced sexual abuse were more likely to have traded sex (Chen, Tyler, Whitbeck, \& Hoyt, 2004; Tyler et al., 2001).

\section{Well-being}

High rates of depressive symptoms have been reported among homeless youth (Whitbeck, Hoyt, \& Bao, 2000) and these youth are generally more vulnerable; consequently, they are more likely to be taken advantage of and may be pressured or coerced into trading sex (Tyler \& Johnson, 2006). Another risk factor that has been found to be associated with trading sex is partner sexual coercion. One qualitative study found that homeless young women were often coerced or pressured by friends or partners to trade sex because these people also benefit from this exchange by obtaining money or drugs (Tyler \& Johnson, 2006). Being taken advantage of by friends and partners is not uncommon among street youth (Janus, Archambault, Brown, \& Welsh, 1995; Tyler, Hoyt, Whitbeck, \& Cauce, 2004). As such, homeless youth may not only be coerced by their partners to do things that they do not want to, such as being forced to have sex with them, but it is expected that partner sexual coercion will also be associated with homeless young adults trading sex.

\section{Street survival}

Homeless youth often participate in deviant subsistence strategies, such as conning and stealing, in order to obtain the things that they need (Hagan \& McCarthy, 1997; Tyler \& Johnson, 2004; Whitbeck \& Hoyt, 1999). Youth who engage in delinquent activities may also be at greater risk for trading sex for items that they deem necessary and when they have no other means of obtaining them (Greene et al., 1999; Mallory \& Stern, 2000). In addition to delinquency, having friends who trade sex is also a risk factor for youth themselves engaging in this same activity (Tyler et al., 2000; Tyler \& Johnson, 2006). This can occur via associations with these friends as well as through pressure and coercion from friends who trade sex (Tyler \& Johnson, 2006). Finally, although few studies have examined whether being propositioned to trade sex has an effect on the likelihood of young people doing so, one qualitative study found that not all youth who were propositioned to trade sex actually did so whereas other youth who were not propositioned to trade sex personally sought out people with whom to trade sex (Tyler \& Johnson, 2006).

Because rates of trading sex have been found to vary by sexual orientation, gender, age, and race (Clatts \& Davis, 1999; Greene et al., 1999; Moon et al., 2000; Tyler \& Johnson, 2006; Whitbeck, Chen, Hoyt, Tyler, \& Johnson, 2004), these characteristics were controlled for in the current study. Additionally, youths' education level, employment status, and family income may also influence their availability of resources, which, in turn, may affect whether they trade sex. As such, the analyses also controlled for these three variables.

Few studies have examined risk factors associated with trading sex among homeless youth in general and homeless young adults (i.e., 19-25 years) in particular. Although earlier studies examined the frequency of trading sex and other risky behaviors, many have not gone beyond correlations and testing for mean differences. Therefore, controlled multivariate analyses examining risk factors associated with trading sex among homeless young adults is needed. Accordingly, the purpose of the current study was to use multivariate analyses to examine risk factors for trading sex, including family background, well-being, and street survival factors among a sample of homeless young adults. The proposed study expands and strengthens the existing body of literature in this area because (1) it focused on homeless young adults ages 19-25 for whom little to no research exists and (2) this group experiences numerous risk factors associated with trading sex. Additionally, because trading sex can have long-term negative effects on homeless youths' health and well-being, it is important to learn more about the associated risk factors so that appropriate intervention is possible.

\section{Hypotheses}

Based on the above mentioned literature, it was hypothesized that sexual abuse, number of times running away, depressive symptoms, partner sexual coercion, delinquency, having friends who have traded sex, 
and being propositioned to trade sex would all be positively associated with the young person trading sex. The multivariate analyses controlled for age, race, family income, youth education, youth employment status, gender, and sexual orientation because rates of trading sex have been found to vary for many of these variables.

\section{Method}

\section{Participants}

Data for the current study were from the Homeless Young Adult Project. Over a period of approximately one year (from April 2004 through June 2005), 199 young adults were interviewed in three midwestern cities in the U.S. Of this total, 144 were homeless and 55 were currently housed. Participants comprising the housed sample were obtained via peer nominations from the homeless youth in the study. The reason for the smaller number of housed youth was that the majority of homeless youth had a difficult time nominating housed peers because most of their friends were homeless. However, 28 out of the 55 housed young adults had run away from home at least once. In fact, the 28 young adults who were currently housed ran more times, on average, than the currently homeless youth $(M=5.72$ vs. 4.99$)$, though this difference was not statistically significant. What differentiated these two groups for the moment was their current housing status, indicating that homelessness is a situation that is very fluid and not easily defined. The final sample for the current study included 151 young adults who were currently homeless or who had a history of running away or being homeless and who had valid data on all of the variables of interest.

Females accounted for $36 \%$ of the sample $(N=55)$ and males accounted for $64 \%(N=96)$. Approximately $16 \%$ of participants self-identified as gay, lesbian, or bisexual (GLB). Young adults ranged in age from 19 to 26 $(M=21.58$ years). Twenty-two percent of the sample was non-white and $32 \%$ of young people reported that their caretaker was on welfare or not working when they were growing up. The majority (59\%) of youth worked less than full time and 36\% had only completed grade 11 or less in terms of their education. Sixty-nine percent of youth had run or left home between one and three times and $47 \%$ reported experiencing at least one type of sexual abuse. Nineteen percent of young adults had experienced at least one type of partner sexual coercion and $44 \%$ reported having friends who traded sex. Over onethird $(36 \%)$ of young people said they had been propositioned to trade sex. Finally, 15\% of participants reported having ever traded sex.
Procedure

Interviews were conducted by experienced interviewers who had worked on past projects dealing with atrisk youth, had served for several years in agencies and shelters that support homeless young people, and were very familiar with local street cultures, such as knowing where youth congregate. Additionally, all interviewers had completed the Collaborative Institutional Review Board (IRB) Training Initiative course for the protection of human subjects in research.

Interviewers approached shelter residents and located eligible participants in areas of the three cities where street youth congregate. Young people were interviewed using a systematic sampling strategy that maximized locating homeless youth. This approach was used because it is well established that it is not possible to randomly sample homeless populations (Wright, Allen, \& Devine, 1995). Study eligibility required young people to be between the ages of 19 and 25 and homeless. Interviews were conducted in shelter interview rooms, quiet corners of fast food restaurants, or coffee shops. Informed consent was obtained from all young adults prior to participation in the study. Participants were told about the confidentiality of the study, that their participation was completely voluntary, and that they had the right to refuse to answer any question or end the interview at any time. The interviews lasted approximately one hour and all participants received a modest reimbursement for their involvement. Referrals and services (e.g., shelter, counseling services, and food services) were offered to the young adults at the time of the interview. Although screening rates were not formally tallied, field interviewers reported that very few young adults refused to participate. The IRB at the author's institution approved all procedures.

\section{Measures}

\section{Number of times run}

Number of times run was a single item indicator that asked youth to report the number of times that they have ever run away from home. This variable was collapsed due to skew into the following categories: $1=$ once, $2=2$ or 3 times, $3=4$ or 5 times, $4=6-10$ times, $5=11-20$ times, $6=21-51$ times. The mean was 2.2 indicating that, on average, youth ran away from home between two and five times.

\section{Sexual abuse}

Sexual abuse was measured using seven items. Participants were asked how often an adult had done the fol- 
lowing things to them before they were on their own and while they were under the age of 18: some of these items included being asked by an adult to do something sexual, watching an adult do something sexual, and having the participant touch an adult sexually. Due to skewness, each item was dichotomized $(0=$ never and $1=$ at least once) and then summed. Because the variable was still highly skewed, the resulting item was dichotomized into $0=$ no sexual abuse and $1=$ experienced at least one form of sexual abuse at least once.

\section{Depressive symptoms}

Depressive symptoms consisted of 10 items from a short form of the Center for Epidemiological Studies Depression scale (Radloff, 1977). Interviewers asked participants how many days in the previous week they experienced depressive symptoms, such as being bothered by things that do not usually bother them, having trouble keeping their mind on things, feeling low in energy, feeling restless, and feeling lonely. Responses ranged from $0=$ rarely or none of the time (less than one day) to $3=$ most or all of the time (5-7 days). Certain items were reverse coded and then all items were summed so that higher scores indicated more depressive symptoms. Overall, $58 \%$ of the sample scored above 10 on the depression scale, indicating that they screened positive for depressive symptoms. Cronbach's alpha was .80 .

\section{Sexual coercion}

Sexual coercion from a partner was measured using three items identified via factor analysis from the Revised Conflict Tactics Scale (Straus, Hamby, Boney-McCoy, \& Sugarman, 1996). These items asked participants how often their partner made them have sex without a condom, used threats to get them to have sex, and used force (like hitting, holding down, or using a weapon) to make them have sex. Response categories ranged from $0=$ never to $6=$ more than 20 times. These items loaded strongly on a single factor and correlated well. A single dichotomous variable was created in which a score of 0 indicated that the youth had never experienced any of the three types of partner sexual coercion, and a score of 1 indicated that they had experienced at least one type of sexual coercion at least once. This item was dichotomized due to skew.

\section{Delinquency}

Delinquency was measured with six items which asked youth how often they engaged in delinquent activities, such as selling stolen items, breaking into a house or store, stealing things from cars, using stolen credit cards, stealing something worth more than $\$ 50$, and selling drugs. Response categories ranged from $0=$ never to $3=$ many times ( 5 or more). Items correlated well and loaded strongly on a single factor. A summed scale was created and the average score on the delinquency variable was 3.43. Cronbach's alpha was .84.

\section{Friends traded sex}

Friends traded sex was a single item that asked young people if any of their friends had ever traded sex for food, money, and/or shelter. Responses included $0=$ no and $1=$ yes.

\section{Propositioned to trade sex}

Propositioned to trade sex was measured with a single item that asked youth if anyone had ever asked them to have sex in return for something, such as money, a place to stay, or drugs. Response categories were $0=$ no and $1=$ yes.

\section{Control Variables}

Age was a continuous variable that measured how old youth were in years at the time of the interview $(M=21.58)$. Race was coded $0=$ non-white and $1=$ white. Youth were asked, "Which of the following categories best describes your parent/caretaker income?" They were then given a card that listed a series of possible response categories that included $0=$ "welfare or not working", $1=$ " $1-4,999$ ", $2=$ " $5,000-9,999$ ", $3=$ "10,000-14,999", and so on, up to $14=$ "100,000+." This variable was dichotomized to account for skew, and a new variable was created in which $0=$ had an income of greater than $\$ 0$, and 1 = was on welfare or was not working. Youth education was a continuous variable that ranged from $0=$ completed the 7 th grade or less to $7=$ completed some college. Employment was coded $0=$ less than full time (i.e., less than $40 \mathrm{~h}$ per week) and $1=$ employed full time (i.e., $40 \mathrm{~h}$ per week or more). Gender was coded $0=$ male and $1=$ female. Sexual orientation was assessed by asking participants how they would describe their sexual orientation. Those who said they were straight or heterosexual were coded as 1 and those who said they were gay, lesbian, or bisexual were coded as 0 .

\section{Traded sex}

The dependent variable, traded sex, was a combination of items which asked participants if they have ever traded sex in return for something, such as money, a place to stay, or drugs. Additionally, an open-ended question asked youth what kinds of things they had 
done to get by on the streets when they had few other options. Those who indicated that they had engaged in trading sex for any type of item were also included in this count. The final variable was dichotomized due to skew into $0=$ never traded sex and $1=$ traded sex at least once.

\section{Data analysis}

Bivariate associations between ever trading sex and dichotomous correlates were assessed by contingency table analysis; prevalence ratios and their $95 \%$ confidence intervals (CI) were calculated. Cohen's $d$ was used to assess the effect size between ever having traded sex and the continuous correlates and the logistic regression model included adjusted odds ratios (AOR) and their 95\% CI.

\section{Results}

\section{Bivariate associations}

Table 1 displays bivariate associations between the dichotomous variables and ever having traded sex. Nine associations were examined and of these, six were statistically significant. As shown, non-white youth were approximately two and a half times more likely to have traded sex than white youth. GLB youth were almost two and a half times more likely to have ever traded sex compared to heterosexual youth. Youth who did not experience sexual abuse were $59 \%$ less likely to have ever traded sex compared to youth who were sexually abused. Young people who experienced no partner sexual coercion and those whose friends never traded sex were $58 \%$ and $88 \%$ less likely, respectively, to have ever traded sex compared to those who experienced partner sexual coercion and who had friends who traded sex. Finally, youth who were never propositioned to trade sex were $91 \%$ less likely to have ever traded sex compared to youth who were propositioned to trade sex.

Table 2 displays the effect size between continuous variables and ever having traded sex using Cohen's $d$. As shown, the effect size for age and depressive symptoms with ever having traded sex was large (i.e., above .8) while the effect size for delinquency and trading sex was medium to large (i.e., almost .7). The effect size was small for education and trading sex whereas the effect for number of times run away and trading sex was small to medium (Cohen, 1992).

Multivariate associations

Table 3 displays the multivariate associations. A total of 14 variables were entered into the equation and, of these,
Table 1. Bivariate associations between dichotomous correlates and ever having traded sex $(N=151)$

\begin{tabular}{|c|c|c|c|c|c|}
\hline Correlate & $N$ & $\begin{array}{l}\% \text { who had } \\
\text { traded sex }\end{array}$ & $\mathrm{PR}^{\mathrm{a}}$ & $95 \% \mathrm{CI}^{\mathrm{b}}$ & $p$ \\
\hline \multicolumn{6}{|l|}{ Racial category } \\
\hline Non-white & 33 & 27.3 & 2.48 & $1.16-5.28$ & .019 \\
\hline White & 118 & 11.0 & & & \\
\hline \multicolumn{6}{|l|}{ Caretaker's income } \\
\hline Income $>\$ 0$ & 103 & 13.6 & .816 & $.37-1.81$ & ns \\
\hline Welfare or not working & 48 & 16.7 & & & \\
\hline \multicolumn{6}{|l|}{ Employment } \\
\hline$<40 \mathrm{~h} /$ week & 89 & 16.9 & 1.49 & $.65-3.45$ & ns \\
\hline$\geq 40$ h/week & 62 & 11.3 & & & \\
\hline \multicolumn{6}{|l|}{ Gender } \\
\hline Male & 96 & 11.5 & .57 & $.27-1.23$ & ns \\
\hline Female & 55 & 20.0 & & & \\
\hline \multicolumn{6}{|l|}{ Sexuality } \\
\hline GLB & 24 & 29.2 & 2.47 & $1.13-5.41$ & .027 \\
\hline Heterosexual & 127 & 11.8 & & & \\
\hline \multicolumn{6}{|l|}{ Sexually abused } \\
\hline Not sexually abused & 80 & 8.8 & .41 & $.18-.96$ & .031 \\
\hline Sexually abused & 71 & 21.1 & & & \\
\hline \multicolumn{6}{|l|}{ Partner sexual coercion } \\
\hline No sexual coercion & 122 & 11.5 & .42 & $.19-.90$ & .027 \\
\hline Sexual coercion & 29 & 27.6 & & & \\
\hline \multicolumn{6}{|l|}{ Friends trading sex } \\
\hline Friends never traded sex & $x 85$ & 3.5 & .12 & $.04-.40$ & .001 \\
\hline Friends traded sex & 66 & 28.8 & & & \\
\hline \multicolumn{6}{|c|}{ Propositioned to trade sex } \\
\hline Never propositioned & 97 & 3.1 & .09 & $.03-.28$ & .001 \\
\hline Propositioned & 54 & 35.2 & & & \\
\hline \multicolumn{6}{|l|}{ a Prevalence ratio } \\
\hline${ }^{\mathrm{b}}$ Confidence interval & & & & & \\
\hline
\end{tabular}

six were significant. Results revealed that for each additional year of age, youth were $37 \%$ more likely to have traded sex $(\mathrm{AOR}=1.37 ; 95 \% \mathrm{CI}=.99-1.90)$. White youth were $84 \%$ less likely to have traded sex than nonwhite youth (AOR $=.16 ; 95 \% \mathrm{CI}=.03-.77)$. Youth who had been employed full time were $80 \%$ less likely to have traded sex $(\mathrm{AOR}=.20 ; 95 \% \mathrm{CI}=.05-.85)$. For every one unit increase in depressive symptoms, there was an $11 \%$ increase in the likelihood of ever having traded sex $\quad(A O R=1.11 ; \quad 95 \% \quad C I=.99-1.24)$. Additionally, those who had friends who traded sex were approximately five times more likely to have ever traded sex themselves compared to those with no friends who had traded sex $(\mathrm{AOR}=5.17 ; 95 \% \mathrm{CI}=.95-28.12)$. Finally, youth who were propositioned to trade sex were almost five and one-half times more likely to have ever 
Table 2. The effect size between continuous correlates and ever having traded sex $(N=151)$

\begin{tabular}{|c|c|c|c|c|c|}
\hline Correlates & \multicolumn{2}{|c|}{ Never traded $\operatorname{sex}(N=129)$} & \multicolumn{2}{|c|}{ Traded sex $(N=22)$} & Cohen's $d$ \\
\hline Depressive symptoms & 12.18 & 6.37 & 17.41 & 6.22 & 0.83 \\
\hline Delinquency & 2.92 & 4.13 & 6.41 & 5.84 & 0.69 \\
\hline
\end{tabular}

Note: Cohen's $d=M_{1}-M_{2} / \sigma_{\text {pooled }}$ where $\sigma_{\text {pooled }}=\left[\left(\sigma_{1}^{2}+\sigma_{2}^{2}\right) / 2\right]^{1 / 2}$. Interpretations of effect sizes are as follows: $d=.2$ is small, $d=.5$ is medium, and $d=.8$ is large (Cohen, 1992)

Table 3. Adjusted odds ratios for correlates of ever having traded $\operatorname{sex}(N=151)$

\begin{tabular}{lcc}
\hline Correlate & $\mathrm{AOR}^{\mathrm{a}}$ & $95 \% \mathrm{CI}^{\mathrm{b}}$ \\
\hline Age & $1.37+$ & $.99-1.90$ \\
White & $.16^{*}$ & $.03-.77$ \\
Welfare or not working & 1.26 & $.27-5.81$ \\
Youth education & 1.41 & $.91-2.19$ \\
Full time employment & $.20^{*}$ & $.05-.85$ \\
Female & 1.10 & $.23-5.34$ \\
Heterosexual & .97 & $.19-5.08$ \\
Number of times run away & 1.36 & $.88-2.10$ \\
Sexually abused & 1.14 & $.24-5.35$ \\
Depressive symptoms & $1.11+$ & $.99-1.24$ \\
Experienced partner sexual coercion & 1.22 & $.27-5.41$ \\
Delinquency & 1.13 & $.96-1.34$ \\
Friends traded sex & $5.17+$ & $.95-28.12$ \\
Propositioned to trade sex & $5.45^{*}$ & $1.02-29.17$ \\
\hline
\end{tabular}

a AOR: Adjusted for the influence of all other variables in the model

b Confidence interval

** .01 level of significance (two-tailed)

*.05 level of significance (two-tailed)

+.05 level of significance (one-tailed consistent with directional hypothesis)

done so compared to youth who had not been propositioned $(\mathrm{AOR}=5.45 ; 95 \% \mathrm{CI}=1.02-29.17){ }^{1}$

\section{Discussion}

This study examined risk factors associated with ever having traded sex among homeless young adults in the midwestern United States. Having more depressive symptoms, having friends who trade sex, and being propositioned to trade sex were significantly associated with homeless young adults having ever traded sex.

\footnotetext{
${ }^{1}$ Collinearity was not a problem in any of the models because vari-
} ance inflation factors were all well below 5 (Menard, 1995).
These findings suggest that homeless young people who are more depressed were also more likely to resort to trading sex. It is possible that depressed youth are more vulnerable and, consequently, they are more likely to be taken advantage of by being pressured or coerced into trading sex (Tyler \& Johnson, 2006). The current study also revealed that having friends who traded sex was a risk factor for youth themselves trading sex. Research finds that being taken advantage of by friends and partners is not uncommon among street youth (Janus et al., 1995; Tyler et al., 2004). It is possible that the youth in the current study were coerced by their friends to trade sex or may have felt obligated to do so. Finally, being propositioned to trade sex was itself a risk factor. Even though $36 \%$ of youth in the current study were propositioned to trade sex, not all of them did so. Additionally, some youth who traded sex were not necessarily propositioned. Being asked to trade sex, however, may make it harder for some youth to refuse, especially if they find themselves in a desperate situation where they lack resources.

The control variables of age, race, and employment were also significant. These findings indicate that older youth were more likely to trade sex, which is consistent with previous research (Whitbeck et al., 2004). It is possible that older youth may be on the streets for longer time periods and have more opportunities for exposure to deviant peers which may result in their becoming embedded within the street culture (Hagan \& McCarthy, 1997; Whitbeck \& Hoyt, 1999) and, as a result, place them at greater risk for trading sex. Youth employed less than full times were also more likely to trade sex compared to their full time employed counterparts. It is likely that many youth who work only part time do not have sufficient means to support themselves and, as a result, may have to resort to trading sex. Finally, results indicated that non-whites were more likely to trade sex compared to their white counterparts. Because Black youth in general face unique stressors, including perceived barriers to receiving services, and indeed report receiving fewer services compared to whites (Scheppers, van Dongen, 
Dekker, Geertzen, \& Dekker, 2006), it is possible that they are less likely to request help and, as a result, have fewer resources available. Trading sex may be one way that some of these youth can meet their daily survival needs.

There were no significant differences between heterosexual and GLB homeless young adults or between males and females. That is, neither group was significantly more likely to have ever traded sex. At the bivariate level, there was a difference with sexual minority youth being significantly more likely to have traded sex but this difference dropped to non-significance when controlling for the other variables in the multivariate model. In contrast, gender was not significant at either the bivariate or multivariate level. Although some studies find higher rates of trading sex for females (Tyler \& Johnson, 2006), other studies find higher rates for males (Greene et al., 1999) at the bivariate level. As such, the findings in the literature are mixed. It is possible that because both males and females spend time on the street, they may have comparable levels of exposure to highrisk individuals and thus may have similar opportunities to trade sex. It is also interesting to note that while the relationship between sexual abuse and trading sex was significant at the bivariate level, it dropped to nonsignificance when controlling for the other variables in the multivariate model. This is somewhat surprising given that prior research has found a positive link between these two variables. Some of this prior research, however, has only examined females and because they are more likely to be sexually abused compared to males, we would expect a positive association to exist for young women. It is also possible that although sexual abuse is an important factor in the prediction of trading sex, perhaps being propositioned and having friends who trade sex are more important and can lead to trading sex regardless of sexual abuse history.

These findings have important implications for those who work with homeless youth and young adults. First, it is possible that the current behavior of many homeless young adults stems from earlier underlying problems. For example, sexually abused youth may be depressed and a higher level of depression is associated with trading sex. As such, case workers and service providers will need to work with youth to help change youths' negative self-image which may be the result of years of abuse and running away from home numerous times. Second, given the negative health outcomes that are associated with trading sex, such as sexual victimization, sexually transmitted diseases, and unwanted pregnancy, understanding these correlates is especially important for case workers and service providers who work with this population so that they can intervene and address these issues before trading sex becomes a way of life and leads to long-term health problems. Third, it is important to provide homeless youth with access to counselors in a non-judgmental setting which may increase the likelihood that they will request help when needed.

Some limitations should be kept in mind when interpreting these results. First, the findings were based on cross-sectional data; although many of these variables were correlated, we cannot assume cause and effect. Second, youth reported on very sensitive topics and it is possible that some of them were unwilling to disclose their participation in some of the activities; therefore, the results may be underestimates of the actual occurrences of high-risk behaviors. Third, youth were asked to report on the behavior of their friends (i.e., friends trading sex) and it is possible that youth were over or underreporting this behavior. Finally, refusals to participate were not systematically recorded.

In conclusion, more research on homeless young adults is needed to examine whether their experiences are similar to those of other age groups. Additionally, though difficult with this population, longitudinal studies are needed that follow homeless young people across time to see whether trading sex becomes a way of life or whether it is more of a short-term response to a desperate situation such as needing a warm play to stay for one night. Further, longitudinal studies are needed to study homeless young adults given that these 19-25 year olds are at a critical transition period when work patterns are typically established and intimate relations are formed. Failure to establish oneself as a young adult may have long-term repercussions including becoming part of a growing older homeless population.

\section{Acknowledgement}

This research was funded by the National Institute of Mental Health (MH 064897), Dr. Kimberly A. Tyler, Principal Investigator.

\section{References}

Beech, B. M., Myers, L., \& Beech, D. (2002). Hepatitis B and C infections among homeless adolescents. Family Community Health, 25, 28-36.

Chen, X., Tyler, K. A., Whitbeck, L. B., \& Hoyt, D. R. (2004). Early sexual abuse, street adversity, and drug use among female homeless and runaway adolescents in the Midwest. Journal of Drug Issues, 34, 1-21.

Clatts, M. C., \& Davis, W. R. (1999). A demographic and behavioral profile of homeless youth in New York City: Implications for AIDS outreach and prevention. Medical Anthropology Quarterly, 13, 365-374.

Cohen, J. (1992). A power primer. Psychological Bulletin, 112, 155-159.

Greenblatt, M., \& Robertson, M. J. (1993). Life-styles, adaptive strategies, and sexual behaviors of homeless adolescents. Hospital and Community Psychiatry, 44, 1177-1180. 
Greene, J. M., Ennett, S. T., \& Ringwalt, C. L. (1999). Prevalence and correlates of survival sex among runaway and homeless youth. American Journal of Public Health, 89, 1406-1409.

Hagan, J., \& McCarthy, B. (1997). Mean streets: Youth crime and homelessness. Cambridge: Cambridge University Press.

Halcon, L. L., \& Lifson, A. R. (2004). Prevalence and predictors of sexual risks among homeless youth. Journal of Youth and Adolescence, 33, 71-80.

Janus, M. D., Archambault, F. X., Brown, S. W., \& Welsh, L. A. (1995). Physical abuse in Canadian runaway adolescents. Child Abuse and Neglect, 19, 433-447.

Kipke, M. D., Unger, J. B., O'Connor, S., Palmer, R. F., \& LaFrance, S. R. (1997). Street youth, their peer group affiliation and differences according to residential status, subsistence patterns, and use of services. Adolescence, 32, 655-669.

Kral, A. H., Molnar, B. E., Booth, R. E., \& Watters, J. K. (1997). Prevalence of sexual risk behaviour and substance use among runaway and homeless adolescents in San Francisco, Denver and New York City. International Journal of STD \& AIDS, 8, 109-117.

Mallory, C., \& Stern, P. N. (2000). Awakening as a change process among women at risk for HIV who engage in survival sex. Qualitative Health Research, 10, 581-594.

Martinez, T. E., Gleghorn, A., Marx, R., Clements, K., Boman, M., \& Katz, M. H. (1998). Psychosocial histories, social environment, and HIV risk behaviors of injection and noninjection drug using homeless youths. Journal of Psychoactive Drugs, 30, 1-10.

Menard, S. (1995). Applied logistic regression analysis. Thousand Oaks, CA: Sage.

Moon, M. W., McFarland, W., Kellogg, T., Baxter, M., Katz, M. H., MacKellar, D., \& Valleroy, L. A. (2000). HIV risk behavior of runaway youth in San Francisco: Age of onset and relation to sexual orientation. Youth $\mathcal{E}$ Society, 32, 184-201.

Overall, C. (1992). What's wrong with prostitution? Evaluating sex work. Signs, 17, 705-724.

Radloff, L. S. (1977). The CES-D Scale: A self-report depression scale for research in the general population. Applied Psychological Measurement, 1, 385-401.

Scheppers, E., van Dongen, E., Dekker, J., Geertzen, J., \& Dekker, J. (2006). Potential barriers to the use of health services among ethnic minorities: A review. Family Practice, $23,325-348$.
Straus, M. A., Hamby, S. L., Boney-McCoy, S., \& Sugarman, D. B. (1996). The revised Conflict Tactics Scale (CTS2); Development and preliminary psychometric data. Journal of Family Issues, 17, 283-316.

Tyler, K. A., Hoyt, D. R., \& Whitbeck, L. B. (2000). The effects of early sexual abuse on later sexual victimization among female homeless and runaway youth. Journal of Interpersonal Violence, 15, 235-250.

Tyler, K. A., Hoyt, D. R., Whitbeck, L. B., \& Cauce, A. M. (2001). The impact of childhood sexual abuse on later sexual victimization among runaway youth. Journal of Research on Adolescence, 11, 151-176.

Tyler, K. A., Hoyt, D. R., Whitbeck, L. B., \& Cauce, A. M. (2004). Risk factors for sexual victimization among male and female homeless and runaway youth. Journal of Interpersonal Violence, 19, 503-520.

Tyler, K. A., \& Johnson, K. A. (2004). Victims and offenders: Accounts of paybacks, invulnerability, and financial gain among homeless youth. Deviant Behavior, 25, 427-449.

Tyler, K. A., \& Johnson, K. A. (2006). Trading sex: Voluntary or coerced? The experiences of homeless youth. Journal of Sex Research, 43, 208-216.

Tyler, K. A., Whitbeck, L. B., Hoyt, D. R., \& Yoder, K. A. (2000). Predictors of self-reported sexually transmitted diseases among homeless and runaway adolescents. Journal of Sex Research, 37, 369-377.

Van Leeuwen, J. M., Hopfer, C., Hooks, S., White, R., Petersen, J., \& Pirkopf, J. (2004). A snapshot of substance abuse among homeless and runaway youth in Denver, Colorado. Journal of Community Health, 29, 217-229.

Whitbeck, L. B., Chen, X., Hoyt, D. R., Tyler, K. A., \& Johnson, K. D. (2004). Mental disorder, subsistence strategies, and victimization among gay, lesbian, and bisexual homeless and runaway adolescents. Journal of Sex Research, 41, 329-342.

Whitbeck, L. B., \& Hoyt, D. R. (1999). Nowhere to grow: Homeless and runaway adolescents and their families. New York: Aldine de Gruyter.

Whitbeck, L. B., Hoyt, D. R., \& Bao, W. (2000). Depressive symptoms and co-occurring depressive symptoms, substance abuse, and conduct problems among runaway and homeless adolescents. Child Development, 71, 721-732.

Wright, J. D., Allen, T. L., \& Devine, J. A. (1995). Tracking nontraditional populations in longitudinal studies. Evaluation and Program Planning, 18, 267-277. 